Available online at http://jurnal.stmikroyal.ac.id/index.php/jurteksi

\title{
PERANCANGAN APLIKASI INTERAKTIF PEMBELAJARAN CARA PERAWATAN KESEHATAN GIGI DAN MULUT BERBASIS MULTIMEDIA
}

\author{
Nuriadi Manurung \\ Sistem Komputer, STMIK Royal \\ email: nuriadi1102@gmail.com
}

\begin{abstract}
Education plays an important role in the intellectual life of the nation. So in this case the need of a technology to improve the quality of a school. In addition, it also needs a new and more effective teaching and learning system that is very supportive in the quality and quality of teaching and learning in schools, considering the increasingly sophisticated and the development of science and computerized technology. This study discusses about learning media of oral and dental health. This app is designed using Adobe Flash CS3. This application will simplify the learning process and with this application also the learning process become more interesting, fun, and effective and can help the students / i can learn well and fast and can shorten the learning process that has been submitted manually with guide book.The main purpose of designing this learning media is to make new innovations in teaching and learning process in schools, especially primary school students to be more interesting.
\end{abstract}

Keywords: learning media, learning, innovation, interesting, fun, adobe flash, multimedia.

\begin{abstract}
Abstrak: Pendidikan sangat berperanan penting dalam mencerdaskan kehidupan bangsa.Sehingga dalam hal ini diperlukannya suatu teknologi untuk meningkatkan mutu suatu sekolah. Selain itu juga dibutuhkannya suatu sistem cara belajar mengajar yang baru yang lebih menarik dan efektif yang sangat mendukung dalam kualitas serta mutu belajar mengajar di sekolah, mengingat sudah semakin canggih dan berkembangnya ilmu pengetahuan dan teknologi komputerisasi. Penelitian ini membahas mengenai media pembelajaran kesehatan gigi dan mulut. Aplikasi ini dirancang dengan menggunakan Adobe Flash CS3. Aplikasi ini akan mempermudah dalam proses belajar mengajar dan dengan aplikasi ini juga proses belajar mengajar jadi lebih menarik, fun, dan efektif serta dapat membantu siswa/i bisa belajar dengan baik dan cepat serta dapat menyingkat waktu proses belajar yang selama ini disampaikan secara manual dengan panduan buku.Tujuan utama perancangan media pembelajaran ini adalah untuk membuat inovasi baru dalam proses belajar mengajar di sekolah khususnya siswa/i sekolah dasar agar lebih menarik.
\end{abstract}

Kata kunci: media pembelajaran, belajar, inovasi baru, menarik, menyenangkan, adobe flash, multimedia. 
Available online at http://jurnal.stmikroyal.ac.id/index.php/jurteksi

\section{PENDAHULUAN}

Dalam era globalisasi pada saat ini informasi sudah menjadi kebutuhan dasar bagi setiap orang dan menjadi fasilitator utama bagi kegiatan-kegiatan yang me-mberikan andil besar terhadap perubahan yang mendasar pada pola pikir manusia. Perkembangan dalam bidang ilmu teknologi dan informasi yaitu komputer membuat manusia menginginkan apa yang kita lakukan ingin serba cepat, mudah dan efesien. Perkembangan dalam bidang ilmu teknologi khususnya computer juga telah membuka peluang seluas-luasnya kepada para pakar dan para pengambil keputusan, baik yang bergerak dibidang ekonomi, pemerintahan, pendidikan dan sebagainya untuk menyelesaikan semua permasalahannya dengan menggunakan komputer. Hal ini dikarenakan di dalam komputer tersebut terdapat bermacammacam aplikasi yang bisa digunakan.

Pada saat sekarang ini, kemampuan komputer dapat dimanfaatkan diberbagai bidang untuk mengajar, memberikan informasi, dan menyajikan hiburan melalui multimedia sesuai dengan ke-pentingan user (pengguna). Pe-nyajian multimedia tidak hanya mencakup informasi dari televisi, tetapi image, video, dan lain-lain dapat dikembangkan sendiri. Dengan adanya teknologi multimedia itu, berbagai kepentingan di bidang bisnis, pendidikan danhiburan dalam mencapai tujuannya akan lebih mudah.

Dengan teknologi informasi yang berbasis multimedia diharapkan bisa memberikan peranan penting dalam proses penyaluran informasi. Informasi disebarluaskan melalui banyak cara salah satunya dengan aplikasi multimedia, khususnya dibidang pendidikan.Apabila membahas tentang mutu pendidikanmaka tidak lepas dari kegiatan belajar mengajar di sekolah yang merupakan kegiatan paling penting dan mendasar. Jadi, berhasil atau tidaknya tujuan pendidikan bergantung pada bagaimana proses belajar yang dialami siswa sebagai peserta didik.

Perancangan media pembelajaran di SD Negeri 017725 lestari tentang cara perawatan kesehatan gigi dan mulut merupakan suatu aplikasi yang seharusnya sudah bisa diterapkan di era modern ini. Pengetahuan tentang kesehatan gigi dan mulut hanya didapat melalui referensi buku. Para murid hanya diperlihatkan gambar satu per satu oleh guru melalui metode ceramah. Dengan adanya media pembelajaran berbasis multimedia ini tentunya akan membuat proses belajar mengajar menjadi lebih menarik dan diharapkan dapat meningkatkan motivasi serta hasil belajar siswa.

\section{METODOLOGI}

Metode yang digunakan dalam pengembangan sistem pada penelitian ini adalah metode SDLC yaitu berupa tahapantahapan sebagai berikut:

1. Analisis (Analysis)

Dalam tahap ini dilakukan pendefinisian masalah (meliputi mendefinisikan sasaran dan batasan sistem, mendefinisikan masalah yang dihadapi, mengidentifikasi penyebab masalah), dan analisis kebutuhan sistem (meliputi analisis kebutuhan hardware, kebutuhan software, kebutuhan pengguna, dan kebutuhan informasi).

2. Perancangan (Design)

a. Merancang Konsep

Pada tahapan ini yaitu merancang konsep yang menentukan keseluruhan pesan dan memeriksa semua urutan aplikasi yang akan dibuat.

b. Merancang isi

Setelah merancang konsep yang telah disusun kemudian dapat dirancang isi mengenai apa yang disampaikan pada pembelajaran aksara jawa yang akan dibuat, rancangan isi yang dimasukkan kedalam informasi yang disampaikan haruslah sesuai dengan konsep 
Available online at http://jurnal.stmikroyal.ac.id/index.php/jurteksi

yang disusun serta tidak menyimpang dari tujuan, tentunya konsep yang inovatif dan unik, kami memadukan tiga unsur penting dalam multimedia yaitu teks, gambar dan suara dan animasi dimana teks digunakan untuk menyampaikan informasi secara visual, suara, animasi digunakan mengisi latar dan gambar untuk latar belakang tampilan aplikasi tersebut.

c. Merancang Naskah

Dalam tahap ini dirancang sebuah naskah berupa spesifikasi lengkap dari teks dan narasi untuk aplikasi yang akan dibuat

d. Merancang Storyboard

Pada tahapan ini menuangkan apa yang ada didalam naskah kedalam gambar nyata yang menggambarkan suatu urutan atau alur cerita yang diusulkan untuk aplikasi media pembelajaran.

e. Merancang grafik

Merancang grafik meliputi merancang grafik dua dimensi (meliputi: merancang garis, merancang bentuk, merancang warna, dan merancang format), merancang audio, merancang animasi yang akan digunakan dalam aplikasi pembelajaran.

3. Implementasi (Implementation)

Setelah sistem dianalisis dan didesain secara rinci, maka akan menuju tahap implementasi. Implementasi merupakan tahap merealisasikan sistem yang baru dikembangkan supaya nantinya sistem tersebut siap diimplementasikan sesuai dengan yang diharapkan. Tahapan yang termasuk dalam tahap ini adalah coding (pengkodean), testing (pengujian), installation (instalasi/pemasangan).

a. Coding (Pengkodean)

Coding merupakan tahap implementtasi dimana dilakukan pengkodean berdasarkan hasil rancangan yang telah dibuat sehingga berbentuk sistem yang sedemikian rupa seperti yang sudah direncanakan. Pengkodean ini dilakukan dengan me-nggunakan Flash Lite 1.1 ActionScript.

b. Testing(Pengujian/pengetesan)

Tujuan utama dari pengetesan ini adalah untuk memastikan elemenelemen atau komponen-kompenen dari sistem telah berfungsi sesuai dengan yang diharapkan. Pengetesan perlu dilakukan untuk mengetahui kelemahan-kelemahan atau kesalahan-kesalahan yang mungkin terjadi. Pada tahap pengetesan ini dilakukan dua macam pengetesan yaitu pengetesan sistem dan pengetesan penerimaan.

(1) Pengetesan sistem Mengetes berfungsinya aplikasi media pembelajaran secara keseluruhan.

(2) Pengetesan penerimaan

Pengetesan yang dilakukan dengan metode Alpha test. Pengetesan dilakukan oleh para pengguna umum. Pada pengetesan ini dilihat kualitas dari aplikasi, sudah sesuai dengan apa yang diharapkan oleh pengguna atau belum. Pengetesan ini juga dilakukan untuk mendapatkan tanggapan dari pengguna tentang keramahan program dan tampilan.

(3) Installation (Instalasi/pemasangan)

Instalasi merupakan tahap dimana aplikasi media pembelajaran yang dibuat dipasangkan atau diinstal pada komputer atau laptop.

\section{HASIL DAN PEMBAHASAN}

\section{Memproduksi Aplikasi}

Dalam memproduksi media pembelajaran ini dibagi menjadi dua 
Available online at http://jurnal.stmikroyal.ac.id/index.php/jurteksi

proses, yaitu proses pengumpulan bahan/materi dan proses editing dengan menggunakan beberapa software.

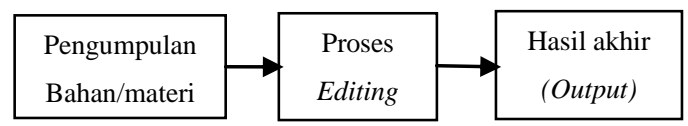

Gambar 1. Proses Produksi Aplikasi

a. Pengumpulan Materi

Materi yang dimaksud adalah tentang cara perawatan kesehatan gigi dan mulut rekaman suara sebagai penjelasan dalam bahasa indonesia yang diperlukan untuk pembuatan media pembelajaran ini.

b. Proses Editing

Di dalam proses pembuatan media pembelajaran ini, editing yang dilakukan tidak hanya memerlukan satu perangkat lunak, tetapi dilakukan dengan beberapa perangkat lunak. Untuk lebih jelasnya, proses pembuatan/editing media pembelajaran tersebut dapat dilihat pada gambar di bawah ini.

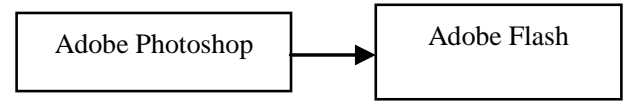

\section{Gambar 2. Proses Editing}

\section{Pengeditan Media Pembelajaran dengan Adobe Flash.}

Adobe Flash CS6 digunakan untuk menyusun semua materi yang telah disiapkan menjadi file multimedia flash. Pembuatan media pembelajaran ini memerlukan 1 file utama yaitu "tugas ku.swf", dan folder "sound" (tempat meletakkan file yang berhubungan dengan suara atau musik). Berikut proses pembuatan tugas ku.swf:

1. Membuat filebarudari menu "File New", memilih "Flash File (ActionScript 2.0"), Save As "Aplikasi Utama.fla"inipada folder yang samadengan file-file materi pendukung yang lainnya.

2. Membuat ukuran lembar kerja pada menu "properties" menjadi witdh 800 px hight 600 px.

3. Membuat background dengan cara memilih menu "file - import - import to library" dan pilih beberapa gambar yang sudah disediakan untuk dijadikan latar belakang pada media pembelajaran ini. Kemudian masukkan gambar dari "library" kedalam timeline lembar kerja dengan cara men-drag.

4. Membuat layout materi, layout materi ini berisikan gambar-gambartentang cara perawatan kesehatan gigi dan mulut. Membuatnya dengan cara memilih menu "file - import - import to library" dan pilih gambar sebagai latar belakangdan juga tentang cara perawatan kesehatan gigi dan mulut yang sudah di import untuk dijadikan isi materi pada media pembelajaran ini. Kemudian masukkan gambar dari "library" kedalam timeline lembar kerja dengan cara men-drag.

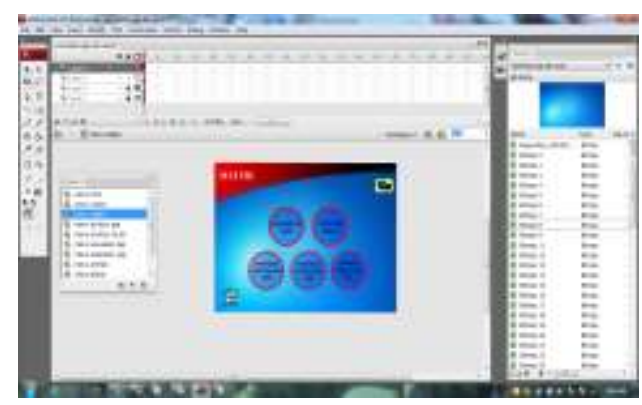

Gambar 3. Pembuatan Background

5. Memasukkan musik background dan rekaman suara yang dijadikan sebagai pengisi suara pada bagian materi. Memasukkan music background dengan cara membuat ter-lebih dahulu layer bernama "sound, selanjutnya pilih menu "file - import - import to library" dan pilih sebuah file musik mp3 yang sudah disediakan untuk dijadikan musik background pada media pembelajaran ini. Kemudian masukkan musik mp3 tersebut dari "library" kedalam layer "sound" didalam lembar kerja dengan cara 
Available online at http://jurnal.stmikroyal.ac.id/index.php/jurteksi

men-drag dan pada library lakukanlah linkage agar mudah dalam penavigasian. Sama halnya dengan memasukkan musik pada background, memasukkan rekaman suara pada bagian materi dengan cara pilih menu "file - import - import to library" dan pilih file rekaman yang sudah disediakan untuk dijadikan pengisi suara pada bagian materi di media pembelajaran ini. Kemudian masukkan rekaman tersebut dari "library" kedalam layer "Timeline" didalam lembar kerja dengan cara men-drag.

6. Membuat contoh quisdapat diawali dengan membuat sebuah layer pada lembar kerja adobe flash tepatnya pada frame 1, kemudian dilanjutkan dengan membuat sebuah judul dan input text untuk pengisian nama pengguna, dan di Timeline berikutnya berisi soal-soal seputar tentang cara perawatan kesehatan gigi dan mulut. Contoh quis ini berupa soal-soal pilihan ganda, setiap jawaban yang benar mendapatkan nilai 20 .

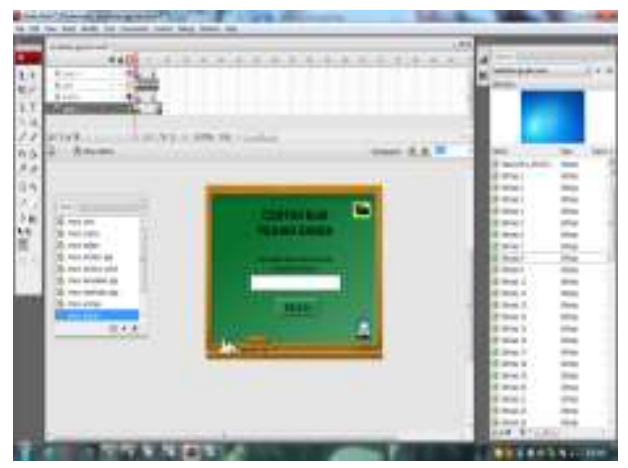

Gambar 4. Tampilan awal Contoh Kuis

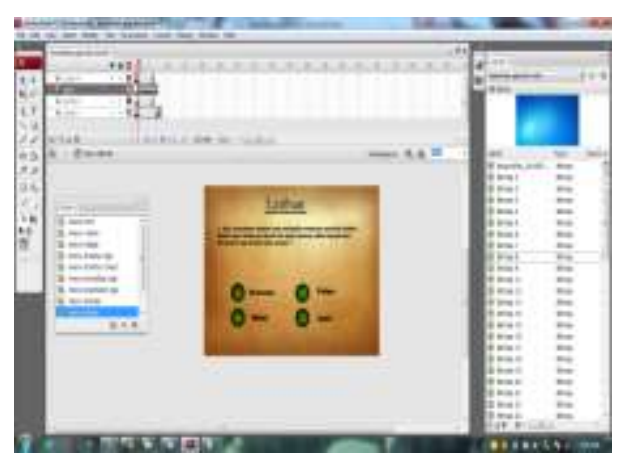

Gambar 5. Tampilan Soal Quis Pilihan Ganda.

7. Membuat Profil dapat diawali dengan membuat sebuah layar pada lembar kerja Adobe Flash tepatnya pada frame 3 , kemudian dilanjutkan dengan membuat sebuah text tulisan yang menjelaskan tentang profil user.

\section{Uji Coba Program}

Dalam melakukan pengimplementasian media pembelajaran berbasis multimedia flash ini, perlu dilakukan uji coba kembali apakah setiap bagian-bagian atau komponen-komponen program tersebut dapat berjalan dengan baik sesuai yang dirancang atau tidak. Caranya dengan menekan pada keyboard "ctrl + enter".

Berikut ini adalah tampilan disaat kita menjalankan aplikasi tersebut:

\section{Halaman Intro}

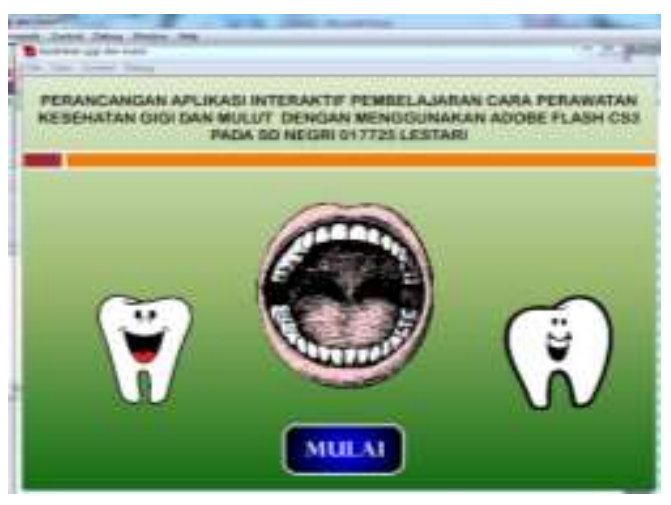

Gambar 6. Tampilan Halam Intro

\section{HalamanMenu}

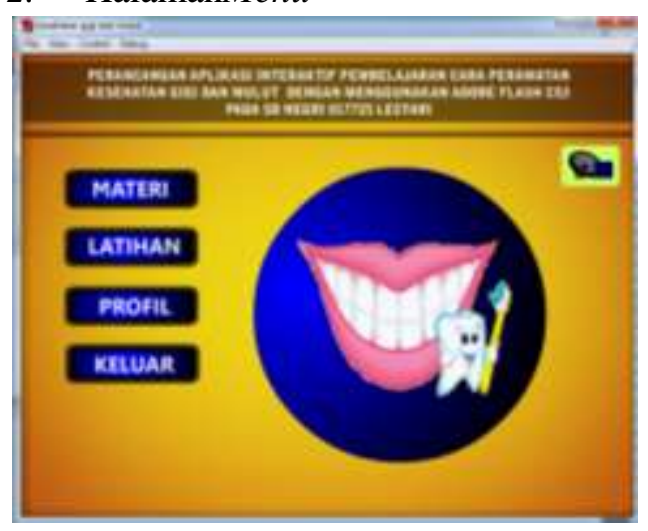


Available online at http://jurnal.stmikroyal.ac.id/index.php/jurteksi

Gambar 7. Tampilan Halaman Menu Utama.

3. Halaman Belajar

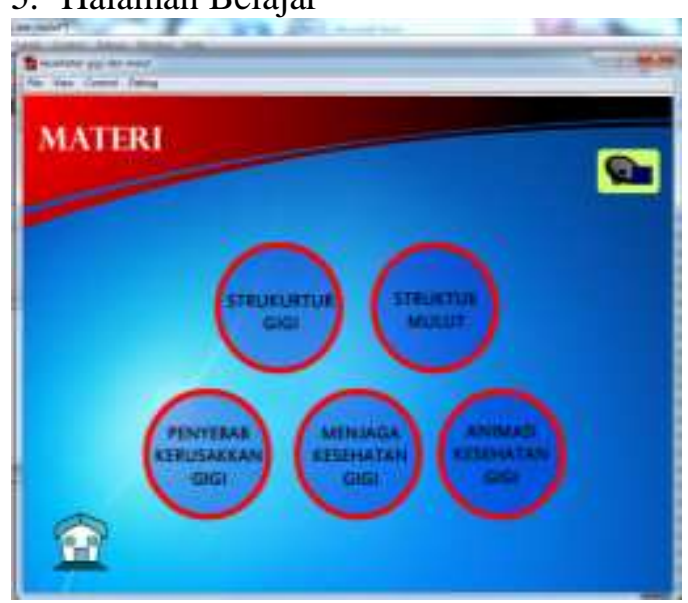

Gambar 8. Tampilan Halaman Belajar.

4. Halaman Struktur Gigi

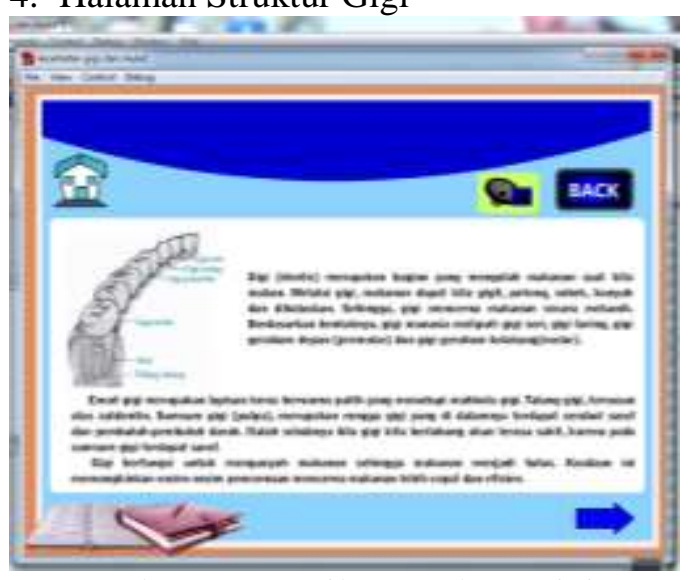

Gambar 9. Tampilan Struktur Gigi.

5. HalamanStruktur Mulut Manusia

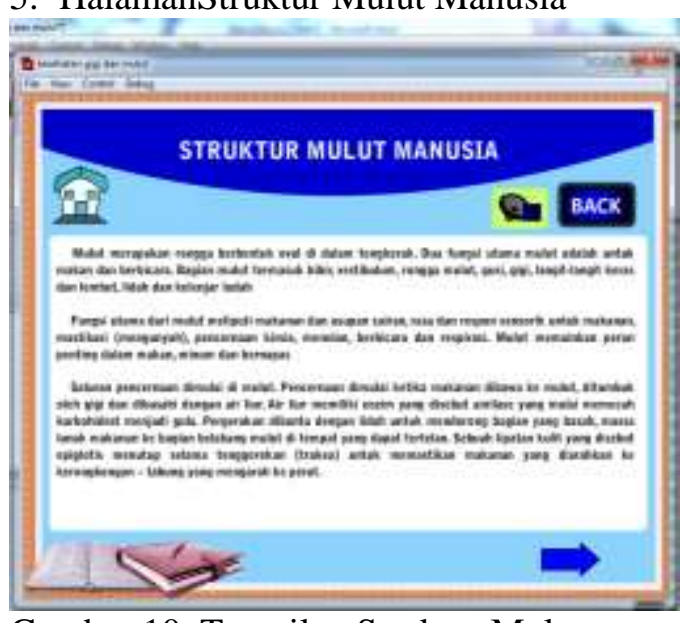

Gambar 10. Tampilan Struktur Mulut Manusia.
6. Halaman Materi Penyebab Kerusakan Gigi

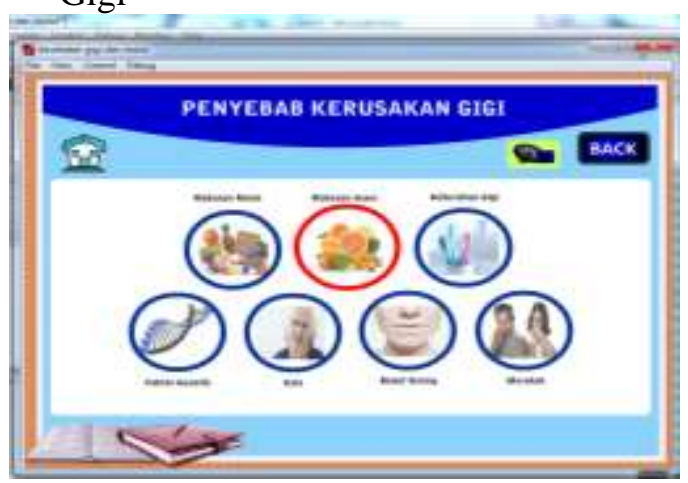

Gambar 11. Tampilan Materi Penyebab Kerusakan Gigi.

7. Halaman Materi Cara Menjaga Kesehatan Gigi

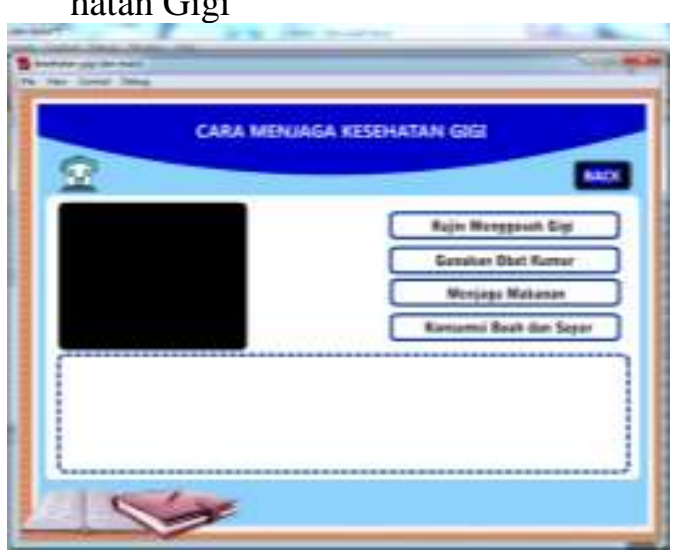

Gambar 12. Tampilan Materi Cara

Menjaga Kesehatan Gigi.

8. Halaman Tampilan Animasi Kesehatan Gigi

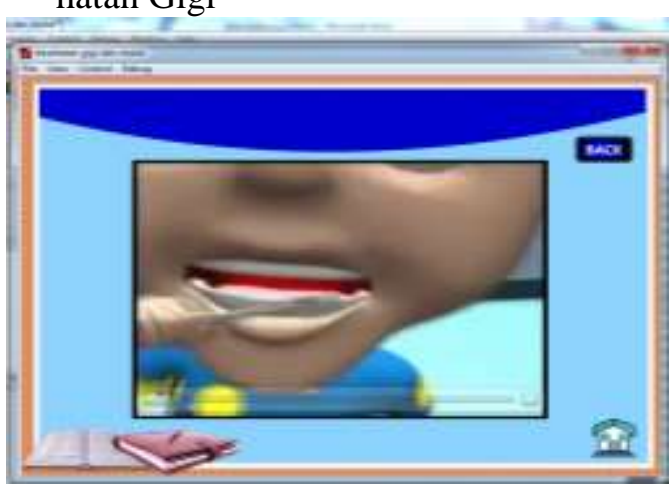

Gambar 13. Tampilan Animasi Kesehatan Gigi. 
Available online at http://jurnal.stmikroyal.ac.id/index.php/jurteksi

9. Halaman Tampilan Latihan

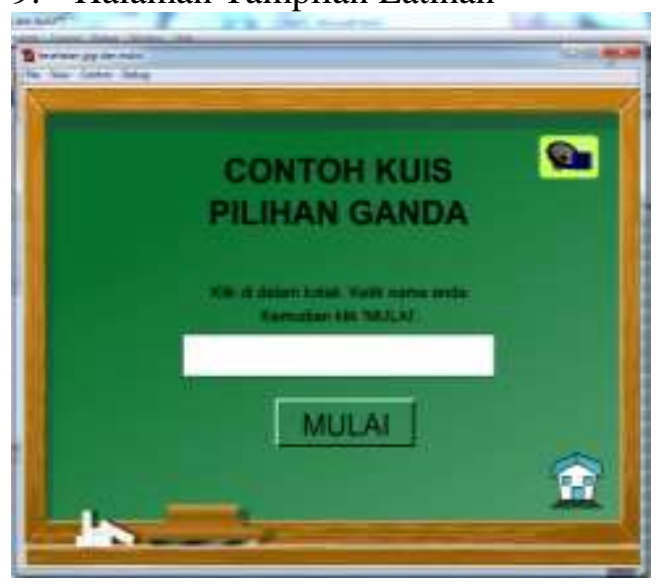

Gambar 14. Tampilan Latihan

\section{Evaluasi Aplikasi}

Aplikasi ini merupakan aplikasi media pembelajaran. Yang kesemuanya itu diusung dan di kemas secara menarik dengan mengangkat konsep education dan hiburan sehingga dapat menarik minat belajar dan mengurangi kebosanan pada peserta didik.

\section{SIMPULAN}

Dari hasil penelitian dan perancangan media pembajaran berbasis multimedia menggunakan Adobe Flash ini, maka peneliti dapat menyimpulkan sebagai berikut:

1. Perancangan aplikasi multimedia menggunakan flash ini mampu membuat dan menjadikan media publikasi dan mempermudah cara mengajar ke peserta didik dari yang

\section{DAFTAR PUSTAKA}

Arsyad, A. (2011) Media Pembelajaran. Jakarta : Paja Grafindo Persada. sebelumnya agar peserta didik termotivasi untuk belajar.

2. Dari proses perancangan media pembelajaran ini dapat diketahui bahwa merancang sebuah media pembelajaran ini perlu dilakukan terlebih dahulu adalah dengan merumuskan permasalahan yang ada, dan mencari alternatif penyelesaian masalah yang ada serta mengimplementasikan perancangan dalam bentuk program aplikasi flash.

3. Apabila diaplikasikan, maka aplikasi ini dapat memberikan opsi baru bagi sekolah-sekolah dalam penyampaian informasi bagi guru, agar guru tersebut lebih semangat memberikan materi yang akan disampaikan kepada siswa-siswi ke dalam kelas.

4. Dengan adanya penyajian media yang berbasis multimedia ini ada beberapa komponen multimedia didalamnya maka aplikasi ini terlihat lebih menarik dan atraktif.

5. Dengan menggunakan aplikasi media pembelajaran ini diharapkan dapat membantu siswa-siswi bisa belajar dengan baik dan cepat serta dapat menyingkat waktu proses belajar yang selama ini disampaikan secara manual dengan panduan buku

6. Dengan adanya media pembelajaran berbasis multimedia ini maka proses belajar mengajar jadi lebih menarik dan fun.
Sunyoto, A. (2010). Adobe Flash + $X M L=$ Rich Multimedia Application . Yogyakarta: Andi 
Available online at http://jurnal.stmikroyal.ac.id/index.php/jurteksi 
Available online at http://jurnal.stmikroyal.ac.id/index.php/jurteksi 
Jurnal Pena Edukasi

Vol. 4 No. 2, Maret 2017
ISSN 2407-0769 e-ISSN 2549-4694 